\title{
Quality of life in surgically palliated complex congenital heart disease
}

\author{
F A Casey, B G Craig, H C Mulholland
}

\begin{abstract}
The outcome of surgical palliation was evaluated in 26 children with complex cyanotic congenital heart disease. Outcome was examined in terms of ongoing symptoms, exercise tolerance, and the ability to participate in normal childhood activities. An activity score was calculated and each child performed graded treadmill exercise testing.

Breathlessness (24 (92\%) children), respiratory infections (nine (35\%) children), and leg cramps (eight $31 \%$ ) children) were the most common physical disorders. Although formal exercise testing showed a clear reduction in exercise tolerance compared with age and sex matched controls, palliation had allowed $23(89 \%)$ to function with moderate exercise limitation, three (11\%) having severely limited activity. Parents underestimated the child's exercise tolerance in $80 \%$ of cases. Sixteen $(62 \%)$ patients attended school full time, eight $(31 \%)$ attended part time, and two $(8 \%)$ received only home tuition.

Palliative surgery can give children with a single functional ventricle a level of activity which allows them to take part in most childhood activities. Subjective estimates of exercise tolerance are inaccurate in this group of children, and formal exercise testing can contribute useful information to decision making about further surgical intervention.

(Arch Dis Child 1994; 70: 382-386)
\end{abstract}

As a result of continuing improvements in cardiac surgery and perioperative care most children with congenital heart disease now have the potential to survive to normal adulthood. ${ }^{2}$ There remains, however, a group of children with complex cyanotic heart disease for whom 'curative' surgery is not possible. These are mainly children born with a single functional ventricle (univentricular heart). In previous generations such children were considered inoperable and most died in early infancy, 34 but now many have palliative surgery in an attempt to prolong life. But what are the results of such an operation? Published work confirms the increased duration of survival after palliative shunt surgery. ${ }^{5}$ Trusler and Williams reported a $70 \%$ survival rate at 15 years after shunt surgery in patients with tricuspid atresia. ${ }^{6}$ There have, however, been no comprehensive studies evaluating the quality of life of such survivors. The aim of this study was to critically evaluate the results of palliative surgery in a group of children with complex heart disease on the basis of their ongoing symptoms and level of activity.

\section{Patients and methods}

PATIENT SELECTION

Patients with surgically palliated complex heart disease were identified from the computerised database of the paediatric cardiology department of the Royal Belfast Hospital for Sick Children. The charts of prospective patients were then examined and those with chromosomal abnormalities or major non-cardiovascular problems were excluded from the study; patients who had required an operation for any other reason (for example, repair of tracheo-oesophageal fistula) were thus not included. The parents of 26 suitable children (21 boys, five girls) gave written consent for their child to take part in the study. All patients had a single functional ventricle. Table 1 gives the diagnostic subcategories of the study group. In 13 children the systemic ventricle was a morphologically left ventricle and in 13 the systemic circulation was supported by a morphologically right ventricle.

All patients had at least one palliative operation. In $19(73 \%)$ children the initial procedure was a Blalock Taussig shunt, in five $(19 \%)$ a Watterston shunt, and in two $(12 \%)$ pulmonary artery banding. In three cases the initial shunt surgery was combined with atrial septectomy. Sixteen $(62 \%)$ children had a single operation, eight $(31 \%)$ required two operations, and two ( $8 \%$ ) had three operations. The mean age at the most recent operation was 3.55 years. The mean postoperative interval was $5 \cdot 44$ (range $2 \cdot 1-12 \cdot 8$ ) years.

The control group, matched for mean age and sex distribution, consisted of 26 children who had attended the paediatric cardiology department on one occasion and been diagnosed as having innocent murmurs. The age range of the children studied was 5 to 15 years, with mean ages of 8.78 years (cases) and $8 \cdot 62$ years (controls).

METHODS

As the aim of the study was to obtain an overall picture of the life of the child, there were two components to the assessment of each

Table 1 Diagnostic categories of the study group

\begin{tabular}{ll}
\hline Diagnosis & $\begin{array}{l}\text { No (\%) of patients } \\
(n=26)\end{array}$ \\
\hline Absent right atrioventricular connection & $8(31)$ \\
Absent left atrioventricular connection & $9(35)$ \\
Double inlet, left ventricle & $5(19)$ \\
Complex double outlet, right ventricle & $4(15)$ \\
\hline
\end{tabular}

Correspondence to: Dr F A Casey, Division of Cardiology, The Hospital for Sick Children, 555 University Avenue, Toronto, Ontario M5G 1X8, Canada. Accepted 24 January 1994 
Table 2 Questionnaire given to parents to assess activity level of child

\begin{tabular}{|c|c|c|c|c|c|}
\hline & 0 & 1 & 2 & 3 & 4 \\
\hline $\begin{array}{l}\text { School } \\
\text { Walking } \\
\text { Stairs } \\
\text { Running } \\
\text { Sport } \\
\text { Tiredness }\end{array}$ & $\begin{array}{l}\text { Home tuition } \\
\text { Wheelchair bound } \\
\text { Never } \\
\text { Never } \\
\text { Never } \\
\text { Always tired }\end{array}$ & $\begin{array}{l}\text { 1/4 Time } \\
\text { Few yards slowly } \\
\text { One flight } \\
\text { Less than } 100 \text { yards } \\
\text { Severely limited } \\
\text { Tired every day }\end{array}$ & $\begin{array}{l}1 / 2 \text { Time } \\
\text { Less than } 100 \text { yards } \\
\text { Two flights difficult } \\
100 \text { yards jogging } \\
\text { Moderately limited } \\
\text { Often tired }\end{array}$ & $\begin{array}{l}3 / 4 \text { Time } \\
\text { Half mile } \\
\text { Two flights easy } \\
\text { Normal speed } 100 \text { yards } \\
\text { Slightly limited } \\
\text { Sometimes tired }\end{array}$ & $\begin{array}{l}\text { Full time } \\
\text { Two miles } \\
\text { Normal } \\
\text { Normal speed } 400 \text { yards } \\
\text { Competitive sport } \\
\text { Normal }\end{array}$ \\
\hline \multicolumn{6}{|c|}{ Please mark the statement on each line which best fits your child over the past year } \\
\hline
\end{tabular}

Table 3 Symptoms of patients and control groups as reported by parents

\begin{tabular}{lcc}
\hline Symptoms & $\begin{array}{l}\text { No (\%) patients } \\
(n=26)\end{array}$ & $\begin{array}{l}\text { No (\%) controls } \\
(n=26)\end{array}$ \\
\hline Breathlessness & $24(92)$ & $2(8)$ \\
Respiratory infections & $9(35)$ & 0 \\
Leg cramps & $8(31)$ & 0 \\
Chest pain & $5(19)$ & $1(4)$ \\
Palpitations & $5(19)$ & $1(4)$ \\
Headaches & $2(8)$ & 0 \\
No symptoms & $2(8)$ & $22(85)$ \\
\hline
\end{tabular}

patient: (a) physical assessment and (b) psychosocial assessment.

The findings of the physical assessment are presented in this paper and those of the psychosocial assessment in a companion paper (F A Casey, D H Sykes, B G Craig, R Power, $\mathrm{H}$ C Mulholland, paper in preparation). The studies were carried out in the paediatric cardiology department on a morning or afternoon suitable for the parents and took about three hours to complete for each patient.

\section{PHYSICAL ASSESSMENT}

A detailed history was taken from each parent to carefully document the child's symptoms. In addition to cardiac symptoms, attention was paid to non-cardiac problems. To assist in assessment of the degree of disability of the patient as perceived by the parents, an activity score was calculated for each child. This was performed using an adaptation of a questionnaire used by Bowyer et al ${ }^{7}$ (table 2) in their study of children after surgical repair of transposition of the great vessels.

Each child had a thorough physical examination, including an assessment of growth by measurement of height, weight, triceps, and subscapular skinfold thickness. In addition, a 12 lead electrocardiogram was recorded and two dimensional echocardiography with Doppler quantitation was carried out.

To obtain an objective measure of exercise tolerance each child performed a symptom limited graded treadmill exercise according to

Table 4 Growth and exercise parameters of 26 children with surgically palliated complex heart disease compared with 26 normal controls. Values are mean (SD)

\begin{tabular}{|c|c|c|c|}
\hline & Patients & Controls & p Value \\
\hline Age (years) & $8 \cdot 78(3 \cdot 3)$ & $8 \cdot 62(2 \cdot 0)$ & 0.91 \\
\hline Birth weight $(\mathrm{g})$ & $3240(500)$ & $3420(500)$ & $0 \cdot 21$ \\
\hline Present weight $(\mathrm{kg})$ & $23.6(9 \cdot 3)$ & $3.42(0.5)$ & 0.008 \\
\hline Present height $(\mathrm{m})$ & $1 \cdot 23(0 \cdot 2)$ & $1 \cdot 31(0 \cdot 1)$ & 0.049 \\
\hline Subscapular skinfold thickness $(\mathrm{cm})$ & $6 \cdot 1(1 \cdot 8)$ & $8 \cdot 7(1 \cdot 7)$ & 0.048 \\
\hline Triceps skinfold thickness & $9 \cdot 7(2 \cdot 6)$ & $12 \cdot 7(4 \cdot 8)$ & 0.009 \\
\hline Activity score & $12(2 \cdot 6)$ & $22(3 \cdot 7)$ & $<0.001$ \\
\hline Maximum exercise time (min) & $7 \cdot 12(1.9)$ & $12.05(1.7)$ & $<0.01$ \\
\hline Resting heart rate (beats/min) & $99(11 \cdot 6)$ & $82(10 \cdot 3)$ & 0.01 \\
\hline Maximum exercise heart rate (beats/min) & $153(20.9)$ & $187(11 \cdot 8)$ & $<0.001$ \\
\hline Resting systolic blood pressure ( $\mathrm{mm} \mathrm{Hg}$ ) & $99(13.9)$ & $111(10 \cdot 8)$ & 0.001 \\
\hline Maximum exercise systolic blood pressure $(\mathrm{mm} \mathrm{Hg})$ & $141(42 \cdot 3)$ & $151(22 \cdot 1)$ & 0.32 \\
\hline
\end{tabular}

the method of Bruce et al. ${ }^{8}$ Oxygen saturation was monitored continuously during exercise using a probe on the right ear lobe. A 12 lead electrocardiogram and blood pressure were recorded every three minutes. A 24 hour electrocardiogram was also recorded.

Statistical comparisons between groups were carried out using Student's $t$ test for independent samples. Linear and stepwise regression was used to analyse data from exercise testing.

\section{Results}

SYMPTOMS

Table 3 gives the symptoms reported by parents and children. Breathlessness (24 (92\%) children) was the most common, and in many the only, symptom. The degree of breathlessness on exertion varied widely, as indicated by the wide variation in walking distance reported by the parents, ranging from a few yards to two miles. Although no child was confined to a wheelchair, three parents found it necessary to use a 'pushchair' for their child so that activities such as going to shops or school were made easier. Although chest pain was reported as being a symptom by five $(19 \%)$ patients, no patient reported chest pain during formal exercise testing. A surprisingly high number $(31 \%)$ of parents and children reported leg cramps as a troublesome symptom. Cramps occurred particularly at night and after excessive exertion. Respiratory infections were reported as a troublesome symptom by $35 \%$ of parents and such infections were the most common 'noncardiac' reason for hospital admission in the study group. Five patients $(19 \%)$ had required hospital admission in the year before the study. In two patients this was due to respiratory infection, one due to abdominal pain, one because of a suspected seizure, and the fifth for cardiac catheterisation.

\section{PHYSICAL EXAMINATION \\ Growth}

Although there was no significant difference in birth weights between the study and control groups, subsequent growth was less good in those with complex heart disease. As a group they were significantly shorter, lighter, and had less subcutaneous fat (table 4). They were not, however, uniformly small; three patients had heights above the 50th centile for age.

\section{Non-cardiovascular problems}

It must be emphasised that this group of patients was deliberately selected to exclude 
Table 5 Activity levels of patients with palliated complex heart disease as reported by their parents

\begin{tabular}{|c|c|}
\hline Activity & No (\%) of children $(n=26)$ \\
\hline \multicolumn{2}{|l|}{ School attendance } \\
\hline Home tuition & $2(8)$ \\
\hline 1/4 Time & 0 \\
\hline $1 / 2$ Time & $3(12)$ \\
\hline 3/4 Time & $5(19)$ \\
\hline Full time & $16(62)$ \\
\hline \multicolumn{2}{|l|}{ Walking } \\
\hline Breathless at rest & $1(4)$ \\
\hline Few yards slowly & $2(8)$ \\
\hline Less than 100 yards & $15(58)$ \\
\hline Half mile & $6(23)$ \\
\hline Two miles & $2(8)$ \\
\hline \multicolumn{2}{|l|}{ Stairs } \\
\hline Never & $3(12)$ \\
\hline One flight & $7(27)$ \\
\hline Two flights difficult & $11(42)$ \\
\hline Two flights no difficulty & $1(4)$ \\
\hline Normal & $4(15)$ \\
\hline \multicolumn{2}{|l|}{ Running } \\
\hline Never & $4(15)$ \\
\hline Less than 100 years & $18(69)$ \\
\hline 100 yards jogging & $3(12)$ \\
\hline Normal speed 100 yards & $1(4)$ \\
\hline Normal speed 400 yards & 0 \\
\hline \multicolumn{2}{|l|}{ Sport } \\
\hline Never & $4(15)$ \\
\hline Severely limited & $13(50)$ \\
\hline Moderately limited & $9(35)$ \\
\hline Slightly limited & 0 \\
\hline Competitive sport & 0 \\
\hline \multicolumn{2}{|l|}{ Tiredness } \\
\hline Always tired & 0 \\
\hline Tired every day & $18(31)$ \\
\hline Often tired & $5(19)$ \\
\hline Sometimes tired & $10(39)$ \\
\hline Normal & $3(12)$ \\
\hline
\end{tabular}

patients already known to have major non-cardiovascular problems, so that the results of palliative surgery for complex heart disease in the otherwise normal patient could be studied.

Neurological examination showed significant abnormalities in one patient. She had weakness of the small muscles of her left hand, was developmentally delayed, and also had a recent history of a possible seizure. She was subsequently shown on computed tomography of her brain to have a small infarct.

PARENTAL ESTIMATES OF ACTIVITY

The results of the activity questionnaire completed by the parents show a clear reduction in activity for the group with complex heart disease compared with controls (table 5). More detailed examination of the individual components of the activity score shows that $15(58 \%)$ of the group with complex heart disease were believed by their parents to be unable to walk a distance of more than 100 yards, and a further two (8\%) were thought to be able to walk only a few yards (table 5). Only four (15\%), however, were reported as never being able to run, and the same percentage never participated in any sporting activity.

Of the $16(62 \%)$ children in the study group attending school full time, one had a classroom assistant assigned to him and another attended a school for physically handicapped children. The latter patient did not have any disability other than congenital heart disease. Two children were felt by their parents to be too incapacitated to attend school and were receiving home tuition. At school most of the patients were able to join their peers in some physical activity, $22(85 \%)$ participating in limited sporting activity.

\section{FORMAL EXERCISE TESTING}

After clinical examination one patient was noted to be cyanosed and breathless with minimal exertion. A treadmill exercise test was not performed in this patient. Echocardiography on this patient, who had two previous Blalock Taussig shunts, indicated that both were barely functional. Patency of the systemic arterial to pulmonary shunts was confirmed by Doppler echocardiography in all other patients with shunts. Successful exercise testing was therefore performed on 25 patients in the study group and 26 controls. Table 4 gives the results of exercise testing. The mean maximum exercise time for the complex group of $7 \cdot 12$ minutes is equivalent to a walking distance of $343 \mathrm{~m}$. The maximum exercise time was not significantly different in those patients in whom the functional ventricle was morphologically right (mean (SD) $6.8(0.81)$ $\mathrm{min}$ ) from those in whom it was morphologically left (mean (SD) 7.5 (1.01) min; $\mathrm{p}=0 \cdot 31$ ).

Only two patients had a measured exercise time of less than $2 \cdot 2$ minutes (equivalent to a walking distance of $100 \mathrm{~m})$. In $20(80 \%)$ patients the parents underestimated the child's exercise tolerance.

Patients had a significantly higher resting heart rate than the controls, but conversely at peak exercise their maximum heart rates were significantly lower than the controls. Resting blood pressure was significantly lower in patients than controls, and also lower at peak exercise, though this difference was not statistically significant (table 4). Linear and stepwise regression analysis showed that the variable correlating best with the measured exercise time was the resting oxygen saturation $(r=0.77 ; \mathrm{p}=0.0001)$ (Figure). Positive correlations that did not reach statistical significance were found with activity score $(r=0.35$; $\mathrm{p}=0.085)$, age $(r=0.31 ; \mathrm{p}=0.13)$, weight $(r=0.30 ; \quad \mathrm{p}=0.14)$, and height $(r=0.34$; $\mathrm{p}=0 \cdot 10)$.

There were no complications during exercise testing of children from either group. None of the patients developed significant dysrhythmia during exercise. Two patients had ventricular ectopics at rest but these were abolished with exercise. A third patient with complex heart disease who was in sinus rhythm at rest developed occasional atrial ectopic beats during exercise.

\section{HOUR ELECTROCARDIOGRAPHY}

Eighteen $(72 \%)$ patients in the study group remained in sinus rhythm throughout the recording period. Five patients alternated between sinus rhythm and nodal rhythm. Three patients had unifocal ventricular ectopics and in one patient these were frequent ( $>50 /$ hour). 


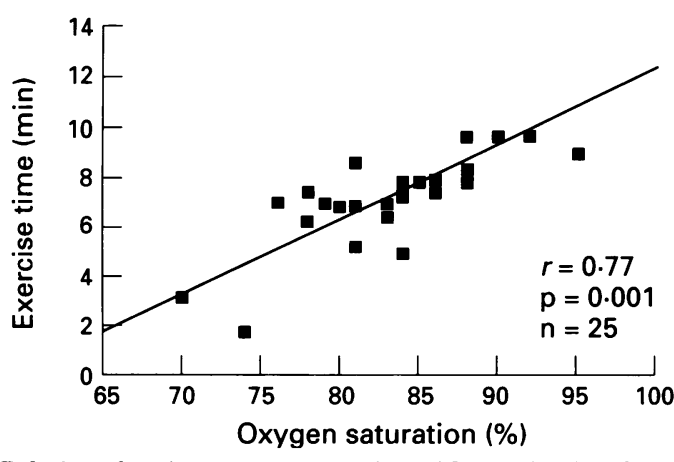

Relation of resting oxygen saturation with exercise time for group with complex heart disease.

\section{Discussion}

The aim of palliative surgery in children with complex heart disease is to relieve symptoms and to allow survival until the child reaches an age where a more major physiological correction such as the Fontan operation ${ }^{9}$ is possible. In this study we have attempted to assess the quality of life which the initial operation gives these children in the early years, which are so crucial to future development.

The major somatic disorder in the children with complex heart disease was breathlessness on exertion. Most children coped well with this problem and had learned to limit their own exercise - for example, by having short rest periods when walking to school or when at play. Parents therefore did not find it necessary to actively limit their child's exercise as the child 'self limited' his or her activity, an observation also made by Cullen et al. ${ }^{10}$

To make clinical management decisions in this group of patients it is important to have an accurate picture of the degree of exercise intolerance. Comparison of the results of formal exercise testing and parental estimates of exercise tolerance indicates that the parents generally underestimated their child's exercise capability. Godfrey also commented on the inaccuracy of parental estimates of effort intolerance. ${ }^{11}$ The mean exercise time of $7 \cdot 12$ minutes on treadmill exercise testing suggests that most of the group cope with moderate functional disability. Three children could be considered to be severely physically incapacitated, two with severely limited measured exercise tolerance and the third too breathless to test. All three have since had further palliative surgery. The results of exercise testing also suggest impairment of the heart rate response to exercise. A reduced heart rate response to exercise has also been shown after palliative shunting in patients with tetralogy of Fallot. ${ }^{12}$

Although there have been studies evaluating exercise ability after Fontan repair ${ }^{13} 14$ less has been published about activity in younger children palliated with shunts. Driscoll et al studied exercise performance in a group of such children aged 6 to 17 years. ${ }^{15}$ They reported a progressive deterioration in exercise tolerance with increasing age and speculated that this may be due to the decreasing function of the chronically overloaded ventricle, or the development of atrioventricular valve regurgitation. They suggested that an operation for the physiological correction of a single ventricle should be considered before or during adolescence. Our study indicates the inaccuracy of subjective estimates of exercise tolerance and therefore the timing of physiological correction should be based on more objective evidence. The major concern in performing exercise testing in these children is the development of arrythmia during the test. Significant arrythmia was not found in any of our study group either during or immediately after exercise. In this study, with adequate explanation and encouragement, children adapted well to the treadmill. Exercise testing with continuous electrocardiographic and oxygen saturation monitoring was a safe and informative procedure. Such exercise testing for example, at yearly intervals - should therefore be helpful in identifying those patients in whom further surgical intervention is indicated.

It was surprising to find that leg cramps were a symptom in eight $(31 \%)$ of the study group. Leg cramps are not usually described as a symptom of congenital heart disease. We could find no other report of this problem in children with complex cyanotic congenital heart disease. The symptom occurred most commonly after excessive exertion and is probably due to an inadequate supply of oxygen to the working muscle.

Although a detailed study of growth was not the primary aim of this study, the children with complex heart disease were found to have grown less well than their peers. They were not, however, uniformly small. The aetiology of growth impairment in cyanotic heart disease is multifactorial and was shown by Feldt et al ${ }^{16}$ not to be directly related to the degree of cyanosis.

The incidence of major neurological abnormality in this specially selected group of patients was low, with only one patient having a significant neurological problem interfering with daily living. Lesser degrees of neurological abnormality may be manifest as behavioural or academic problems in school. An analysis of these parameters in this study group is presented in a companion paper (F A Casey, D H Sykes, B G Craig, R Power, H C Mulholland, paper in preparation).

Central to a satisfactory quality of life for a child is the ability to attend a normal school, provided they can cope with the day to day routine. Full time attendance at normal school was achieved by $16(62 \%)$ of our group with a further $21 \%$ attending half time or more. One child with a moderate limitation of activity as indicated by a treadmill exercise time of 9.1 minutes did not attend school because of maternal anxiety. Communication during the course of the study indicated the teachers' willingness to understand the difficulties, but many were unsure of the limitations to place on the child's activities. Some expressed concern that the child might collapse suddenly if upset or exercising. It is therefore essential that communication with schools is improved, giving teachers a clear indication of what the child can do so that they 
participate alongside their peers as fully as possible.

Palliative surgery can give children with functional single ventricle a level of activity enabling them to take part in most childhood activities. Further study of this group of children after more major physiological correction, such as the Fontan operation, would be useful to objectively assess the improvement in quality of life achieved by such treatment.

The authors thank Dr Chris Patterson for statistical advice. We also thank Jayne Rogers, Colette Anderson, Karen Morrison, and Helen Long for technical assistance. Dr Casey held a research fellowship supported from trust funds of the Royal Belfast Hospital for Sick Children.

1 Manning JA. Insurabílity and employability of young cardiac patients. In: Engle MA, ed. Pediatric cardiovascular disease. Philadelphia: Davis, 1980: 117-27.

$2 \mathrm{Oku} \mathrm{H}$, Shirotani H, Sunakara A, et al. Postoperative longterm results in total correction of tetralogy of Fallot, term results in total correction of tetralogy of Fallot, 1986; 41: 413-8.

3 Report of the New England regional infant cardiac program. Pediatrics 1980; 63 (No 2 suppl): 392-403.

4 Keith JD, Rowe RD, Vlad P. Heart disease in infancy and childhood. New York: Macmillan, 1978: 536.

5 Dick M, Fyler DC, Nadas AS. Tricuspid atresia: the clinica course in 101 patients. Am 7 Cardiol 1975; 36: 327-37.
6 Trusler GA, Williams WG. Long term results of shunt procedures for tricuspid atresia. Ann Thorac Surg 1980, 29: 312-6.

7 Bowyer JJ, Busst CM, Till JA, Lincoln C, Shinebourne EA. Exercise ability after Mustard's operation. Arch Dis Child 1990; 65: 865-70.

8 Bruce RA, Kusumi F, Hosmer D. Maximal oxygen intake and nomographic assessment of functional aerobic impairment in cardiovascular disease. Am Heart $\mathcal{F} 1973$ 85: 546-62.

9 Fontan F, Baudet E. Surgical repair of tricuspid atresia. Thorax 1971; 26: 240-8.

10 Cullen S, Celermajer DS, Deanfield JE. Exercise in congenital heart disease. Cardiology in the Young 1991; 1: 129-35.

11 Godfrey S. Exercise and pulmonary function. In: Anderson RH, Macartney FJ, Shinebourne EA, Tynan M, eds. Paediatric cardiology. Edinburgh: Churchill Livingstone, 1987: 395-417.

12 Crawford DW, Simpson E, McIlroy MB. Cardiopulmonary function in Fallot's tetralogy after palliative shunting operations. Am Heart f 1967; 74: 463-72.

13 Warnes CA, Somerville J. Tricuspid atresia in adolescents and adults: current state and late complications. $\mathrm{Br}$ Hear f 1986; 56: 535-43.

14 Gewilly MH, Lundstrom UR, Bull C, Wyse RKH, Deanfield JE. Exercise responses in patients with congenital heart disease after Fontan repair: patterns and determinants of performance. $\mathfrak{f} \mathrm{Am}$ Coll Cardiol 1990; 6: 1424-32.

15 Driscoll DJ, Staats BA, Heise CT, et al. Functional single ventricle: cardiorespiratory response to exercise. $\mathcal{F ~} \mathrm{Am} \mathrm{Coll}$ Cardiol 1984; 4: 337-42.

16 Feldt RH, Strickler GB, Weidman WH. Growth of children with congenital heart disease. Am $\mathcal{f}$ Dis Child 1969; 117 573-9.

\section{Screening for coeliac disease}

How many papers in the next six years are going to have 'the year $2000^{\prime}$ in the title? I suspect that editors will soon have to start deleting the phrase unless it is strictly relevant. A report in the Lancet with the title 'Coeliac disease in the year 2000: exploring the iceberg' (C Catassi and colleagues, 1994; 343: 200-3), describes research performed in Italy in 1992 and 1993. Blood was obtained by finger prick from 3351 schoolchildren aged 11-15 years. These samples were tested for IgG and IgA antigliadin antibodies. Seventy one showed raised concentrations of both or either and those children were recalled for further testing. This time venous blood was taken and the antigliadin antibody tests were repeated together with a test for antiendomysium antibodies and serum immunoglobulins. Eighteen children were selected for jejunal biopsy on the basis of one or more of: raised IgA antigliadin antibodies, positive test for antiendomysium antibodies, or raised IgG antigliadin antibodies with selective IgA deficiency. Eleven of the 18 biopsies showed the changes of coeliac disease. These children were treated with a gluten-free diet and repeat biopsies on all 11 showed histological improvement. Six of the 11 had had recurrent aphthous stomatitis and most experienced increased well being or accelerated growth on a gluten-free diet.

Malignant disease, especially non-Hodgkin's lymphoma and cancers of mouth, pharynx, or oesophagus, is about twice as common in people with coeliac disease as in the general population and a strict gluten-free diet probably reduces the risk. ${ }^{1}$ This is the main argument in favour of screening and early treatment. The authors of this paper do not discuss the question of cost but the antibody tests are said to be expensive. Exactly how much illness could be prevented by this kind of screening is unknown. More information about costs and benefits is needed before widespread population screening is considered. 